\title{
Study of Failure Mode, Effect and Criticality Analysis
}

\author{
Paul Chang \\ paulchang@mail.buffalo.com.tw
}

\author{
Yi-Lin He \\ r47@mail.buffalo.com.tw
}

\author{
Buffalo Machinery CO., LTD. \\ Taichung City, TAIWAN (R.O.C.)
}

\begin{abstract}
As machining tool systems become increasingly more complicated, the improvement of system scale and functions, increases the probability of system failure. To avoid human injuries caused by system failure, improve system reliability, and enhance the management of system failure and risk control, reliability analysis technology, called FMECA, has been applied many industries since the 1950s. This paper, first, introduces a brief history of FMECA and the current international standard. Second, the core concept and implementation procedure of FMECA will be presented. Finally, the advantages and disadvantages of FMECA and conclusions are provided.
\end{abstract}

Keywords-reliability, FMECA.

\section{INTRODUCTION}

In the early $1950 \mathrm{~s}$, FMECA was originally developed. At first, flight vehicles were propellerdriven for motive power. Propellers were then replaced by jet engines. In the beginning, the manipulation system of propeller-driven flight vehicles was simultaneously hand-controlled and machinery-device-driven. However, this conventional control system was inadequate to control flight vehicles powered by jet-engines and was changed into a hydraulic and electric-based control system.

In addition, the reliability of these devices was very low, and the probability of system failure was high. To avoid flight mission failure and casualties, American aerospace manufacturer, Grumman, developed a reliability analysis technique, called FMECA. The letters " $C$ " and "A" in FMECA refer to Criticality Analysis. The severity of the failure effect can be analyzed and is quantifiable. As the CA is evaluated, the importance of the failure effect is sequenced in advance. Therefore, FMECA could be considered as the pioneer of risk management. Later, as various products and equipment became increasingly more complicated, various industries attempted to avoid the consequence of products and equipment failure. If, in the early stage of product development, the precaution procedures of failure are considered, the risk can be minimized. Therefore, the FMECA analytical technique is performed in some industries to enhance product reliability and security customer satisfaction.

Currently, the relevant standards regarding FMECA are mainly based on regulations of the
American armed forces, MIL-STD-1629, published in 1974; and MIL-STD-1629A revised in 1980 [1]. Various standards are used in other industries, including IEC 812 published by the International Electro-technical Commission (IEC) [2] and SAE J1739 published by the Society for Automotive Engineers (SAE) [3].

\section{THE CONCEPT OF FMECA}

The most frequently used Reliability Analysis Technologies include FMECA and FTA (Fault Tree Analysis), which are usually applied simultaneously. FMECA focuses on "discussions before system failure" per the notion that "prevention is better than cure." Because it allows early planning for precautions of failure, the best time to apply FMECA is in the early stage of product design. During the process of product development, the FMECA technique check-up design can be used repeatedly. The contents should be checked during the whole design procedure. This key concept is similar to Total Quality Management (TQM) [4].

A table, composed of rows, columns, and induction methods is employed in FMECA to help the analysts (R\&D personnel or manufacturers) completely accomplish the failure analysis. The logical relationships between potential and reasonable failure effects and potential failure modes are discovered as shown in Fig. 1.

FMECA can be categorized into Design FMECA (D-FMECA) and Process FMECA (P-FMECA). The D-FMECA covers the product design stage, whereas, P-FMECA examines the possibility of failure during the whole product manufacturing process.

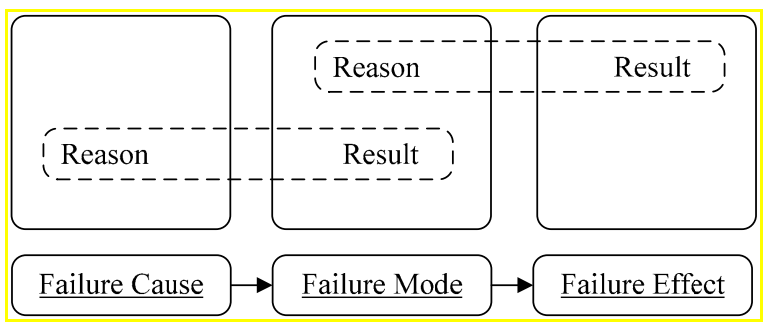

Figure 1. The logical relationship among the Failure Cause, Failure Mode and Failure Effect. 


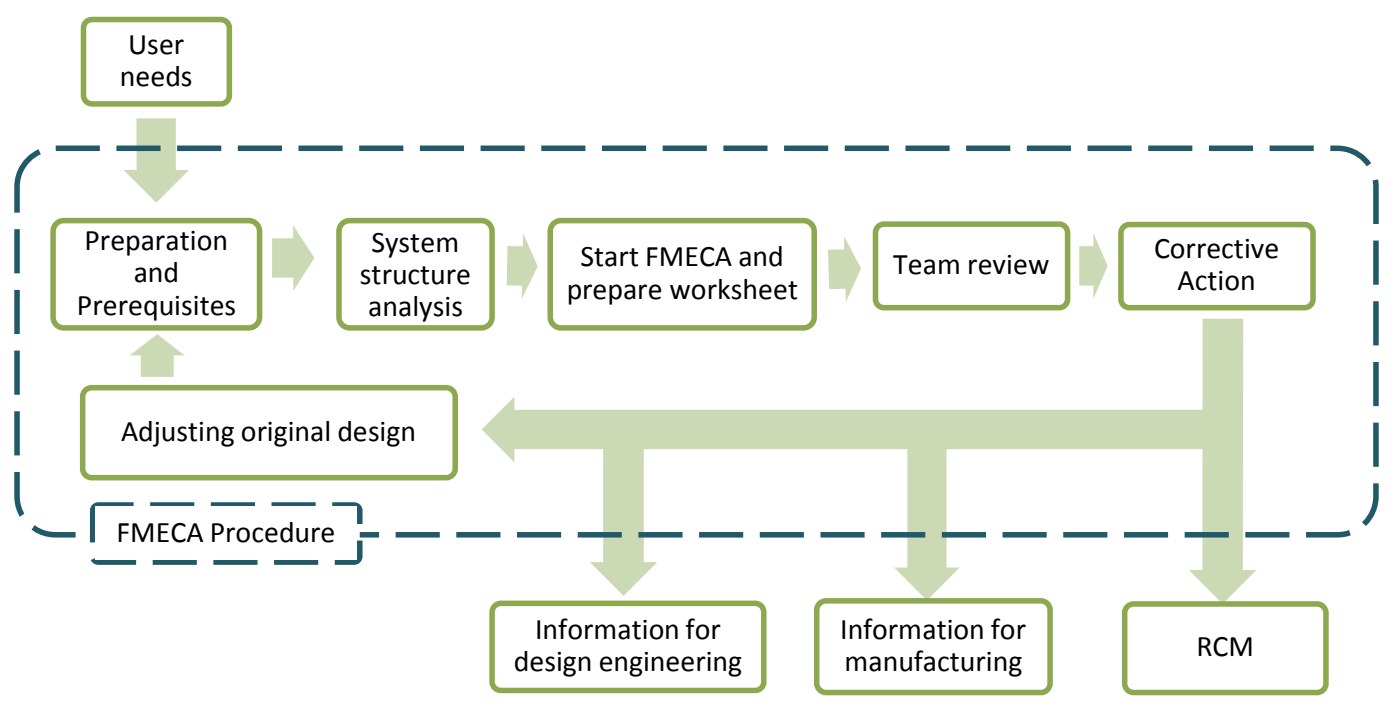

Figure 2. Flowchart to implement FMECA.

\section{THE FMECA PROCEDURES}

The FMECA procedure is shown in Fig. 2. The process comprises lead work, system frame analysis, FMECA and preparation of the worksheet, team inspection and corrective action. In principle, before implementing FMECA, the needs of users must be entered in detail so that sufficient conditions are provided for design engineering. At the Buffalo Company, the Deming Circle (or PDCA cycle) is considered in the FMECA procedure, this circle is not shown in Fig. 2. Finally, after corrective action, the original design/project can be redesigned and adjusted, and the information on the corrective action could be useful in other departments.

\section{A. The Preparation and Prerequisites of FMECA}

Define an analyzable system (confirm system mission, function and specification):

1) Define an analyzable system: This step is to clearly define the system borders, main system function, and main system mission frame; define the environment and system operating condition.

2) Determine the analysis system levels: According to the importance of the system or the severity of the failure mode, determine the targeted analysis levels, depth and range, for example, the subsystem, components, parts or hardware. The lower the analysis level, such as parts, the more complicated, difficult and time-consuming it is. Both of top-down and bottom-up approaches are applicable.

3) Collect useful and meaningful information: To ensure that system is analyzable; sufficient information is needed, including the following three types; (a) system exterior pictures, inspection, circuit diagram, list of parts, interface information or function description, etc. (b) Similar systems design or previous designs; (c) Information from FRACAS (Failure Reporting, Analysis and Correction Action System), such as after-sales service report, experiment report, technical report or abnormal solution report.

\section{B. System structure analysis}

According to the data structure and application, determine the analysis strategy. For example, the Hierarchical Tree (HT) diagram and Functional Block (FB) diagram can be chosen. Taking the HT diagram for example, owing to the layout structure of the HT diagram; it is difficult to link the interaction with these units of the analyzed systems. The HT diagram is more suitable for low system-interaction. The FB flowchart can move easily show the specification and parameters of each block interface and their relations. It can also clarify the system information, signal transformation and transformation of physical quantity, and identify the logical relations of inputs and outputs among the blocks. The FB diagram assists the researchers in understanding the interrelations of every function in the block. Moreover, the FB diagram helps the analyzer know the functionality relationship, such as series- and/or parallel-connection. Depending on the assistance of the FB block diagram, the failure rate at every system level is obtained. The purpose of the reliability block diagram is to calculate the reliability of the whole system.

\section{FMECA and preparation for worksheet}

When the worksheet is ready, as shown in Table 1, the failure analysis work, including the definition, induction and analysis of the failure mode, failure effects and failure criticality is begun. In this table, the column locations can be appropriately adjusted according to the requirements.

1) The element names or numbers are given according to the system structure.

2) Define the element function or mission

3) Define the element working condition, i.e. Idle, Standby and/or Running

4) Failure Mode: Listing potential failure mode. Consider every analysis mode or function condition according to the dissatisfaction of function needs from column two. This can be listed in the failure mode. 
TABLE I. A WORKSHEET SAMPLE OF FMECA

\begin{tabular}{|c|c|c|c|c|c|c|c|c|c|c|}
\hline $\begin{array}{c}\text { Item } \\
\text { Name/ } \\
\text { Number }\end{array}$ & $\begin{array}{c}\text { Element } \\
\text { Function } \\
\text { and Mission }\end{array}$ & $\begin{array}{l}\text { Working } \\
\text { Condition }\end{array}$ & $\begin{array}{l}\text { Failure } \\
\text { Mode }\end{array}$ & $\begin{array}{c}\text { Failure } \\
\text { Effect }\end{array}$ & $\begin{array}{l}\text { Failure } \\
\text { Causes }\end{array}$ & $\begin{array}{c}\text { Failure } \\
\text { Rate }\end{array}$ & Severity & Detection & $\begin{array}{c}\text { Failure } \\
\text { Detection } \\
\text { Methods }\end{array}$ & Note \\
\hline (1) & (2) & (3) & (4) & (5) & (6) & (7) & (8) & (9) & (10) & \\
\hline$\ldots$ & & & & & & & & & & \\
\hline & & & & & & & & & & \\
\hline
\end{tabular}

5) Failure Effects: After the failure mode, list the effects that are shown in other system levels. If there are various types of effects, they can be placed in different columns under the failure effects column, for example, Effect on Safety, Effect on Availability.

6) Failure Causes: These are also known as failure mechanisms, including physical and chemical failure causes (e.g. wear-out, fatigue, corrosion, erosion). The functional failure can also be included. Some failure information can be used, such as internal company failure information or general failure data, such as FMD-97 (Failure Mode/Mechanism Distributions) published by RAC. In general, depending on the depth of the system level, the failure mode contents and nature have a significant difference. Taking the spindle system for example, at the subsystem level, one of the failure modes is called spindle failure; if it occurs at the parts level, the mentioned spindle failure will cause wear-out of the bearing. Both belong to different levels, one at the subsystem level, and the other at the parts level.

7) Failure Rate/Occurrence: This can be quantized to show the frequency of failures. The element failure rate can be predicted or obtained from experiments. The predicted failure rate is originally based on the general data, such as the handbooks MIL-HDBK-217F [5] and NSWC-11 [6], published by U.S. Department of Defense and published by the U.S. Navy, respectively.

8) Severity: This can be quantized. When the failure mode function is at its highest system level, the severity is the reasonable worst case. Generally speaking, personal safety is the most important factor. Financial loss can be considered as well.

9) Detection: Suppose that an element (could be a subsystem, component or part) of the system fails, the ability index of which is detectable before the endusers use the system. The current regulation method can be quantized to determine the difficulty level. The higher the points, the lower the failure-detection probability.

10) Detection of failure: The column defines the detection method to discover the failure mode. The purpose of this step is to define detection methods, as soon as failure occurs. Failure detection can include design control, mistake detection, diagnostic testing, warnings of human senses and different levels. Some failure effects are easy to observe, but the others are hidden. For example, for "motor start failure." the control mode shows "standby." This is a hidden failure mode.

\section{Team Review}

The team review emphasizes the review of failures risks. The team is composed of professional members from various divisions, such as customer service engineers, reliability engineers, product managers or design engineers. Therefore, the team review itself is a team base task that seems to fulfill the participation requirement of TQM [4]. The purpose of the team is to reduce risks caused by failure effects. The priority of the team review is to judge whether the engineering design satisfies the needs according to the mentioned and analyzed failure effects and failure mode, or to reduce the failure-effect-induced risks. Later, the team members propose strategies to reduce risks. Before explaining risk-reducing strategies, the definition of how to quantize the risk index will be explained.

The Risk Matrix or RPN (Risk Priority Number) can be used to quantize the risk index and evaluate the orders when managing failure effects. The definitions of the quantized risk index are slightly different in MIL-STD-1629A and SAE J-1739, but the core concept is identical. The following shows the definition of quantification based on the SAE J-1739 risk index. Severity, occurrence and detection are used in the RPN in SAE J-1739, as shown in Eq. (1). The RPN determines the risk percentage of the failure mode, whose quantification result is the multiplication of $\mathrm{S}, \mathrm{O}$ and $\mathrm{D}$.

$$
\mathrm{RPN}=\mathrm{S} \cdot \mathrm{O} \cdot \mathrm{D} .
$$

Therefore, to reduce the risk index rate, three available strategies can be applied. They are the terms $\mathrm{S}, \mathrm{O}$ and $\mathrm{D}$, in Eq. (1). First, reduce the possibility of failure (or failure rate). Second, reduce the severity of the failure effects. Third, increase the detection rate of failure during the failure process, as shown in Table 2.

In a non-repairable system, the detection term is not effectively practical and meaningful. The factor weight of RPN should be considered. In some nonrepairable systems, the weight of the term $\mathrm{D}$ should be lower than those of the terms $\mathrm{S}$ and $\mathrm{O}$ [7].

TABLE II. THE IMPROVEMENT STRATEGIES OF THE RisK INDEX RATE

\begin{tabular}{|c|c|}
\hline Subject & Strategy \\
\hline Occurrence & Reduce failure rate \\
\hline Severity & Reduce the severity of failure effects \\
\hline Detection & Reduce the failure detection rate \\
\hline
\end{tabular}




\section{E. Corrective Actions}

Several important tasks should be performed for corrective actions: Risk corrective actions, maintenance work, and design engineering. The team review defines only the failure effect, no risk corrective action is introduced. Available corrective actions for consultation: include design change, manufacturing change, inspection plan, security devices, engineered safety features, warning devices and staff training.

By Comparing the RPN before and after correction, the corrected manufacturing techniques/engineering techniques can be written as technical documents or manufacturing documents for personnel reference. After the previous processes are implemented, sufficient information is included in the FMECA worksheet, such as system function, failure occurrence rate, risk and improvement measures. Therefore, the information can be used as references for future design engineering projects. The FMECA worksheet can be the input source for the maintenance project. For example, RCM (Reliability Centered Maintenance) focusing on the reliability rate can be used to define and correct issues regarding maintenance.

FMECA documents help not only project members but also new staff to better understand the products, such as system frames and functions. Moreover, it accumulates experiences of engineers, such as in design and manufacturing. Regarding customers, they will receive highly reliable products and will be better satisfied. The designers could reduce their design change requirements and connect the design personnel with practical theories to achieve higher rigidity of the manufactured workpiece. Manufacturers are able to speed up the manufacturing process.

\section{AdVANTAGES AND DisAdVANTAGES OF FMECA METHODS}

FMECA is a systemized and structured analysis failure reliability engineering technique. The analytical methods not only have high reliability but are also user-friendly. They are also applicable to the analysis of complicated systems. FEMCA might be unsuitable for multi-failure cases because the methods are likely to be tedious and time-consuming. It also regularly fails to consider the failures caused by human mistakes.

\section{CONCLUSION}

The procedure and processes for addressing defects, setbacks and failures in a system can be determined and outlined in an early stage via the systemized process of FMECA. FMECA is an important and practical tool for the improvement of product service and continuous quality. A mature FMECA protocol will be very profitable to customers and the company, by eliminating and reducing injuries caused by design or manufacturing mistakes and unpredictable maintenance work. It will also reduce labor time and cost.

The efficient use of engineering techniques will strengthen the relation between work and theory. The quantification measure of FMECA has a vital position in the field of management and science application. Based on the reliable quantification information and risk order, system setbacks can be detected easily. Thus, corrective measures can be performed more thoughtfully and planned more efficiently.

\section{REFERENCES}

[1] MIL-STD-1929A, "Procedure for performing a failure mode effects and criticality analysis (FMECA)," Dod, Washington, D.C., 1980.

[2] IEC 812, "Analysis techniques for system reliability Procedure for failure mode and effect analysis," Genva, Switzerland, 1985.

[3] SAE J-1739, "Potential failure mode and effects analysis in design (Design FMEA), potential failure mode and effects analysis in manufacturing and assembly processes (Process FMEA)," 2009.

[4] C. K. Chen, "Implementation of total quality management in Buffalo Machinery," Buffalo Machinery Co. Ltd., The Changer, vol. 7, iss. 25, 2015. [Online]. Available: https://www.buffalo.com.tw/journal-preview/index.php?did= $352 \#$ features/27

[5] MIL-HDBK-217F, "Reliability prediction of electronic equipment," U.S. Department of Defense, 1991.

[6] NSWC-11, "Handbook of reliability prediction procedures for mechanical equipment," U.S. Navy, 2011.

[7] Ningcong Xiao, Hong-Zhong Huang, Yanfeng Li, Liping He, and Tongdan Jin, "Multiple failure modes analysis and weighted risk priority number evaluation in FMEA," Engineering Failure Analysis, vol. 18, iss. 4, pp. 1162-1170, Jun. 2011. 